\title{
APPLICATION OF “CHIMERIC” DOUBLE ANTEROLATERAL THIGH FLAPS FOR RECONSTRUCTION OF MASSIVE POSTBURN DEFECT IN HEAD AND FACE (CASE REPORT)
}

\author{
Vu Quang Vinh ${ }^{1}$, Tong Thanh Hai ${ }^{1}$, \\ Hoang Thanh Tuan ${ }^{1}$, Do Trung Quyet ${ }^{1}$, \\ Hoang Tuan Hoang ${ }^{1}$, Khong Hanh Nguyen ${ }^{1}$, Pham Minh Trung ${ }^{2}$ \\ ${ }^{1}$ Le Huu Trac National Burn Hospital \\ ${ }^{2}$ Military Medical Hospital 121/Military Region 9
}

\begin{abstract}
SUMMARY
Head and neck tissue defects are frequently, especially deep and wide defects caused by burning. Choosing sufficient material is a big challenge for surgeons. Using double anterolateral thigh perforator flaps in chimeric type is a new method, a new idea with many advantages for providing large tissue volume to reconstruct extensive defects in face and head area.

We were a success in treating a case of extensive facial burn with complicated lesions by using two anterolateral thighs free flap in chimeric type with single anastomosis. Postoperation, both flaps are survived completely and got good outcomes in both function and aesthetics.
\end{abstract}

Keywords: Burn, chimeric flap, microsurgery.

\section{INTRODUCTION}

Burns are a common accident in daily life, severe burns leave complicated defects. Reconstruction of these defects aims to get back function and esthetic to patients is still a challenge for plastic surgeons. One of the biggest difficulties in choosing the right material including size (usually very wide), similar in color,

Corresponding author: Do Trung Quyet, Le Huu Trac National Burn Hospital

Email: doquyet.vmmu@gmail.com Ngày nhận bài: 07/1/2022; Ngày nhận xét: 15/1/2022; Ngày duyệt bài: 20/1/2022 https://doi.org/10.54804/yhthvb.6.2021.93 thinness for each defect [1].

Some classic skin flaps are used to reconstruct facial defects but there are many limitations in size and can not apply to complicated cases. From this limitation, many authors have proposed methods to enlarge flap size such as expander technique, delayed flap technique, distal anastomosis microsurgery to enlarge the size of skin flap (supercharge) [1]. However, the application of double anterolateral thigh perforator flap in chimeric type is a new idea for the reconstruction of enormous head tissue defects after burning. 


\section{CASE PRESENTATION}

Patient Nguyen Thi N., 49 years old, female, the patient was burned by a coal fire on January $9^{\text {th }}, 2021$ (falling face down in a hot coal basin for many hours due to CO poisoning). Afterburn, the patient was given emergency treatment and managed by removing necrosis and skin grafting. However, she had a massive soft-tissue defect in the head and face area: exposed right temporal skull bone and right cheekbone, surrounded by new scar lesions extending from right temporal region to right chin, retracted scar on the right lateral corner of the eye, progressive osteomyelitis. In handheld Doppler, there was no signal to detect the right superficial temporal artery despite the detected right facial artery.
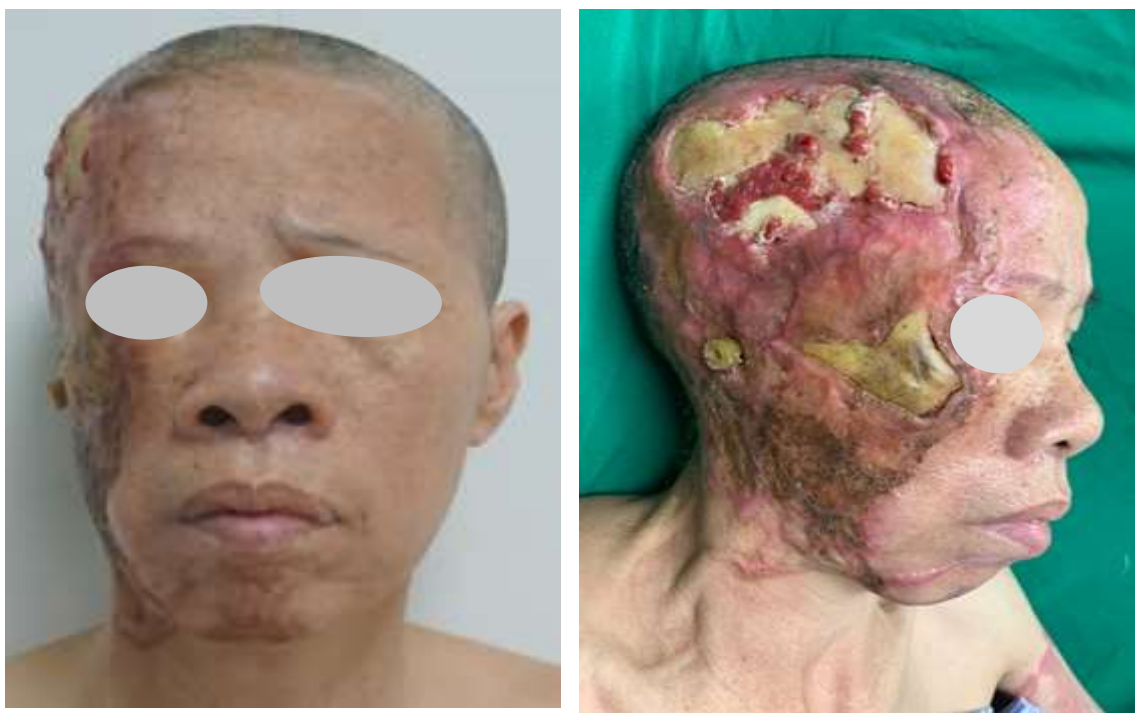

Fig 1. Massive lesions in head and neck postburn

\section{*. Operative treatment}

The patient was assigned to have surgery with the method: Using 2 anterolateral thigh perforator flaps from both sides of the thigh have been anastomosed to create a "chimeric" skin flap, then anastomosed to the facial artery to supply blood.
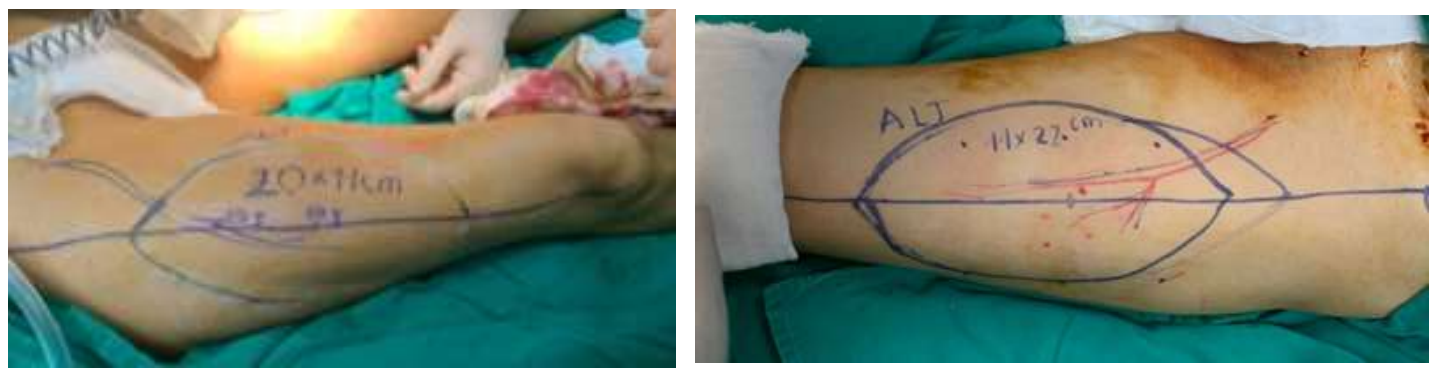

Fig 2. Design the chimeric flaps 
We performed two surgical teams at the same time and dissected the free anterior lateral thigh flap with the right $(R)$ lateral flap size: $20 \times 11 \mathrm{~cm}$; left (L) size: $10 \times 18 \mathrm{~cm}$. After dissection to reveal the pedicle of 2 flaps, it was found that the RALT flap has a longer and smaller perforated vessel than the L-side (especially with small veins), the distal artery was ligated. Cap the left flap, anastomosed the artery of the L-flap with

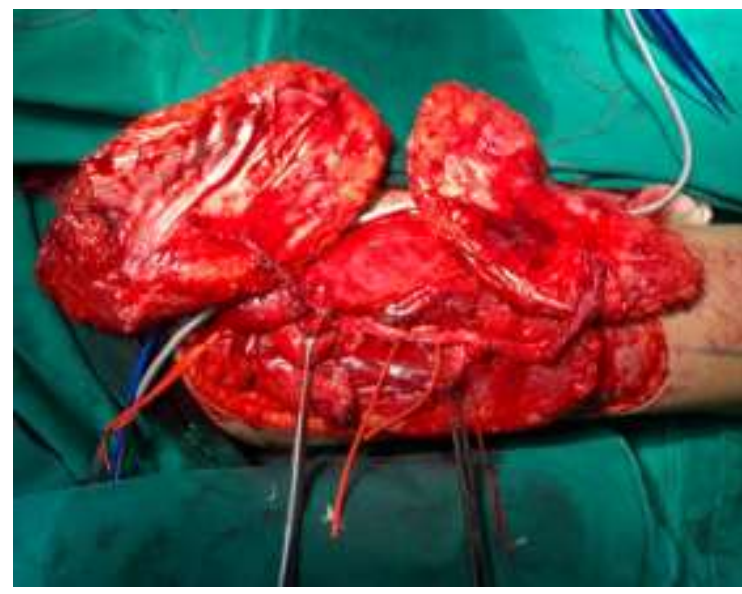

the peripheral end of the R-flap to create a skin flap including 2 ALT flaps connected.

After checking that the circulation through the flap is good, remove the paddle of the R-flap, bring up the whole skin flaps to cover the defect after resection of the head and face, and anastomosed to the right facial vascular bundle. Then, check circulation through the connections and the whole flaps. The surgery was successful after 8 hours.

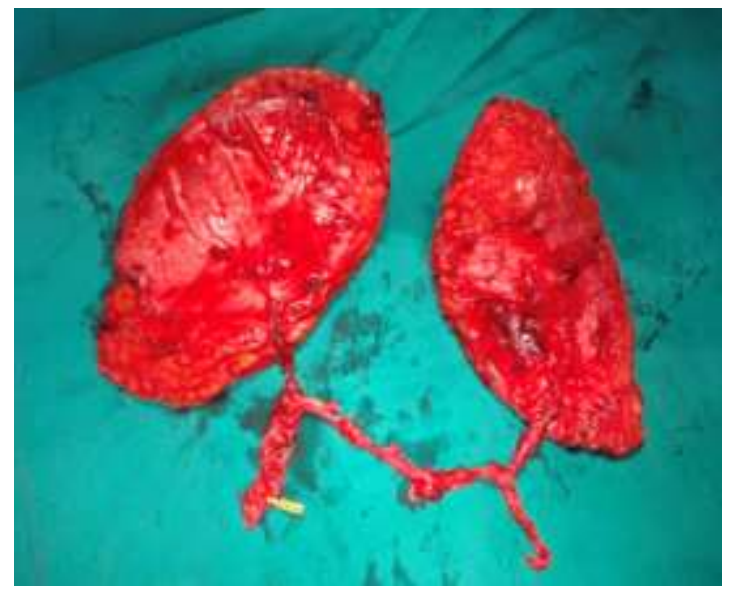

Chimeric flaps

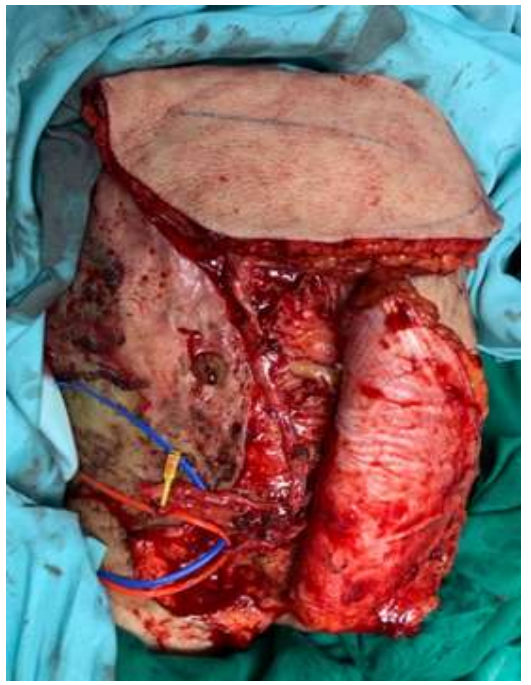

Anastomosis with the right facial artery

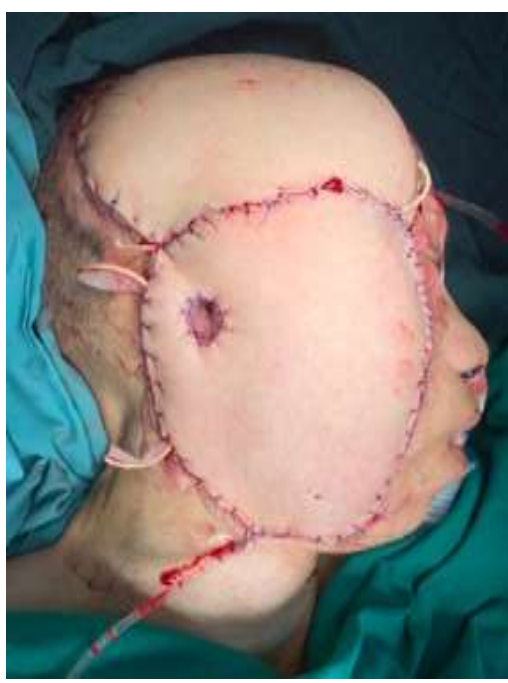

Postoperation

Fig 3. Operative management 


\section{*. Postoperative management and outcomes}

After surgery the patient receives intensive care in the postoperative room, strictly controlling hemodynamic and nutritional. The patient is closely monitored for the circulatory condition of flap: Venous congestion, bleeding in the first 72 hours after surgery. The whole flap was survived completely and the patient was satisfied with the outcomes.
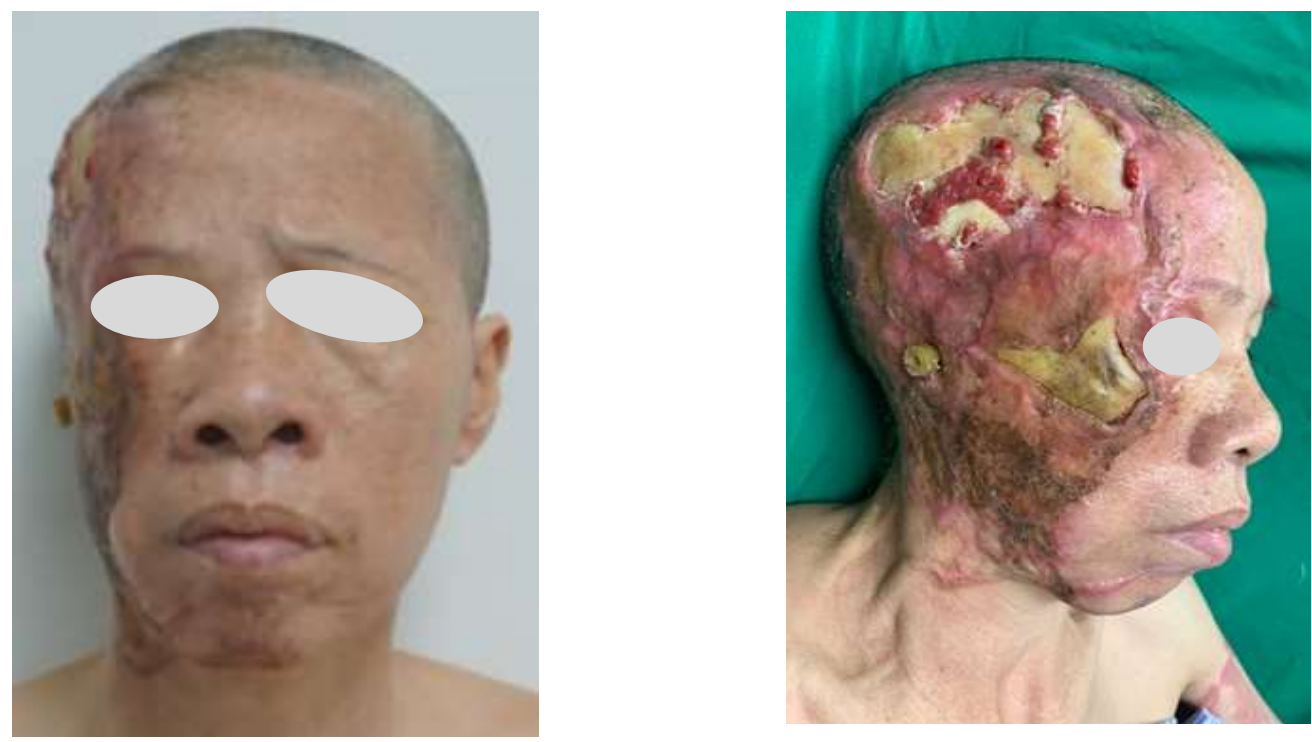

Preoperation
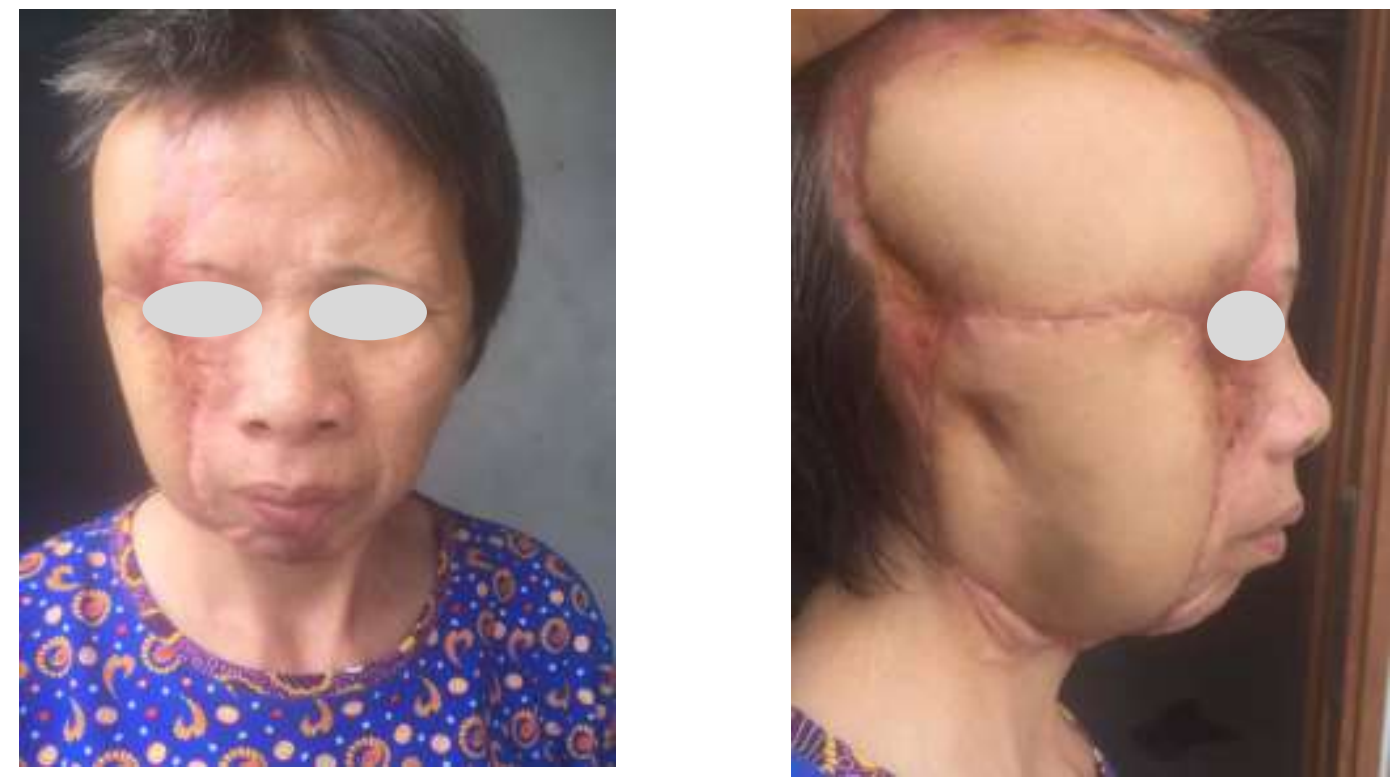

Perforator

Fig 4. Outcomes 


\section{DISCUSSION}

Burn is one reason to cause wide and complex defects on the body, especially the defects in the head and neck-various wounds from skin, muscle, fascia, and bones. The recovery of shape, function, and returning to life to patients is still a significant concern of surgeons. Reconstruction of complex defects is cover or implant and 3-dimensional reconstructive. Therefore, it is necessary to have skin, fascia, fat, and muscle material. And can be divided into different parts that each has its role to achieve the best purpose. Achieving all those factors, with exceptional use of a microsurgery technique of chimeric flap made by two anterolateral thighs (ALT) flap, is the best choice of reconstruction vast and complicated defects on head and neck.

\subsection{Basis of flap selection}

\subsubsection{The features of defect}

The basis for determining the size of the flap and selecting the suitable flap is the size and complexity of the defect. Our patients have an area of vast and deep burn tissue: Approx 3\%, occupying the entire right face area, exposing the right zygomatic bone and temporal-parietal bone; thus, the free flap is the best method. However, the classic free flap won't be covered enough.

In particular, there is damage to the right superficial temporal artery, and the facial arteries are the only source of vessels that can be used for regeneration, so double perforators "super-thin" free flap with circumflex scapular artery perforator and contralateral posterior intercostal perforator... is enough area to cover but not suitable for the recipient.

\subsubsection{Characteristics of Chimeric Flap}

The chimeric flap consists of multiple otherwise independent flaps that each have an independent vascular supply, but in turn, all pedicles are linked to a larger common source vessel. Because these combinations ultimately have only a single source vessel, the microsurgical transfer of these combined multiple flaps can be accomplished while requiring only a single recipient site, which is a major advantage

Hallock G.G. [2] have further subdivided chimeric flaps into three subtypes, again based on their specific blood supply:

\section{+ Branch-based chimeric flaps}

The flap is blooded by branches that directly separate from the vascular original, larger than the perforator from the deep fascial. This type has more giant branches and anatomical constants and allows the simultaneous transfer of multiple and varied tissue components from a single donor site. However, the donor site is often severely damaged. Popular those types of flaps are based on the subscapular artery, circumflex ilium profunda artery.

\section{+ Perforator-based chimeric flaps}

An intact perforator flap with multiple perforators could be considered a form of a conjoined flap, as each perforator has its independent territory. Therefore, the size of the perforator flap is small and isn't an anatomical constant. This typical chimeric 
flap is the anterolateral thigh flap, the deep inferior epigastric artery...

\section{+ Fabricated chimeric flaps}

Attaching otherwise independent flaps to either side branches of the main source vessel or its distal continuation. This type of fabricated chimeric flap thus always requires a micro anastomosis. The fabricated component can be attached to the terminus of the source vessel to the combination (sequential type) or a branch indigenous within the flap (internal type).

In 2015, Kim et al. [3] classified chimeric flaps into four types:

\begin{tabular}{|l|l|l|}
\hline \multicolumn{1}{|c|}{ Chimeric type } & \multicolumn{1}{c|}{ Description } \\
\hline \multirow{3}{*}{$\begin{array}{l}\text { Type I: } \\
\text { Classical } \\
\text { Chimerism }\end{array}$} & $\begin{array}{l}\text { Chimerism by flaps based on named } \\
\text { source vessels or branches. }\end{array}$ \\
\cline { 2 - 3 } & $\begin{array}{l}\text { Type I P: Classical chimeric pattern } \\
\text { including one perforator flap. }\end{array}$ \\
\hline Type II: & $\begin{array}{l}\text { Type II P: Anastomotic chimeric pattern } \\
\text { Anastomotic } \\
\text { Chimerism }\end{array}$ & $\begin{array}{l}\text { including one perforator flap. } \\
\text { Chimerism by microvascular anastomosis } \\
\text { between two flaps. }\end{array}$ \\
\hline
\end{tabular}




\begin{tabular}{|l|l|l|}
\hline & & \\
\hline $\begin{array}{l}\text { Type III: } \\
\text { Perforator } \\
\text { Chimerism } \\
\text { (Hydrism) }\end{array}$ & $\begin{array}{l}\text { Chimerism by flaps based on perforators } \\
\text { only }\end{array}$ \\
\hline $\begin{array}{l}\text { Type IV: } \\
\text { Mixed Chimerism }\end{array}$ & $\begin{array}{l}\text { A chimeric flap is comprised of any } \\
\text { combination of Type I to III chimeric flaps. } \\
\text { A subscript indicates the types of chimeric } \\
\text { flap used in the mixed flap is used into } \\
\text { brackets e.g. } \\
\text { Type IV }(I+I I):\end{array}$ \\
\hline
\end{tabular}

The authors used chimeric flaps in many other forms of use: Peng F. [4], Huang W.C. et al. [5], Houtmeyers P. [6], Shimizu F. [7] used anterolateral thigh chimeric flap to reconstruct through-andthrough cheek defects involving the oral commissure, ....

Most of them are used to reconstruct defects in 3D space while using chimeric flaps to expand the size of the flap has never been mentioned.

\subsection{Advantages and disadvantages of chimeric flaps using chimeric two anterolateral thigh flap}

Song Y.G. et al. [8] first described the flap in 1984 as a flap based on a perforator that comes from the descending branch of the circumflex femoris lateral artery to treat burn scar of head and neck. The advantage of these flaps is the supply amount of tissue skin, fascial, fat, muscle with long and width diameter original artery suitable for microsurgical. Flaps are used flexibly in various forms such as island flap, compound flap, combined with tissue expander to expand area flap, super-thin flap... Exceptional use of the ALT flap is the chimeric flap. These flaps both have the advantage of standard ATL flap and chimeric flap's benefits. 
However, in the world and the country, it has stopped the research and application of perforator chimeric of ALT flap (by Hallock G.G. [2]) or type III (by Kim et al. [3]), no clinical studies have applied ALT in fabricated chimeric style (sequential type) or Type II P (according to Kim et al. in 2015).

\subsubsection{Advantages}

- Larger flap size: The flap is significantly extended due to the flap created by two ordinary ALT flaps, enough to cover wide defect even after removing the nearby scaring.

- High flexible: The defect is not on the same coordinate axis but rather a 3dimensional structural. Thus, this defect is very difficult to reconstruct by the classic flap. When reconstruction, the flap will have to fold or partially cut flap, then the risk-off block blood, necrosis will increase. We use two ALT flaps in chimeric style: one vertical flap covering the defect of the facial area and the other is horizontally above the vertical flap to cover for damage of temporal area due to the high flexibility flap can rotate, change many locations to suit the injury.

- Suitable for recipient artery: When anastomosed, the artery of the L-ALT flap with the peripheral end of the P-ALT flap to create a skin flap include o 2 ALT flaps connected. A single axial axis bloods this flap throughout both flaps. So, when microsurgery, we only connect a single source of circuits to ensure supply for the flap.
Moreover, the upper and lower flaps support each other, helping to reduce the amount of venous congestion when the vein circulation of one of the two flaps is less. This is clear after surgery: One day of stagnant lower flap circulation appears darkened due to smaller veins and longer than upper flap; however, upper flap circulation promotes reflux lower flap. After six days, the lower flap is stable and has no stagnation.

\subsubsection{Disadvantages}

- Although there are many advantages, this flap has some disadvantages: the flap is also thick affecting the emotional and facial expression of patients after surgery. The color of the flap is not similar to the surrounding skin.

\section{- Limitations on sensory recovery}

The scar on the donor site: After surgery, a skin graft is required to cover the donor area, leaving a nasty scar however, this region doesn't affect to aesthetic.

The complicated surgical process requires many cooperating surgical teams; after heavy surgery, patients need intensive care, slow recovery.

\section{CONCLUSION}

Applying two skin flaps on the ALT flaps in the form of "chimeric" is a new method, a completely new idea with many superior advantages for treatment to cover extensive facial and neck defects, especially those reconstructed in three dimensions. 


\section{REFERENCES}

1. Nguyễn Gia Tiến, Vũ Quang Vinh và cộng sự, Nghiên cứu ứng dụng kỹ thuật vi phẩu trong điều trị tạo hình bỏng. Bộ Khoa học và Công nghệ, Hà Nội, 2008.

2. Hallock, G.G., Further clarification of the nomenclature for compound flaps. Plastic and reconstructive surgery, 2006. 117(7): p. 151e-160e.

3. Kim, J.T., Y.H. Kim, and A.M. Ghanem, Perforator chimerism for the reconstruction of complex defects: a new chimeric free flap classification system. Journal of Plastic, Reconstructive \& Aesthetic Surgery, 2015. 68(11): p. 1556-1567.

4. Peng, F., et al., Reconstruction of two separate defects in the upper extremity using anterolateral thigh chimeric flap. Microsurgery, 2013. 33(8): p. 631-637.

5. Huang, W. C., et al, Reconstruction of throughand-through cheek defects involving the oral commissure, using chimeric flaps from the thigh lateral femoral circumflex system. Plastic and reconstructive surgery, 2002. 109(2): p. 433-41; discussion 442.
6. Houtmeyers, P., et al, Reconstruction of the Achilles tendon and overlying soft tissue by free composite anterolateral thigh flap with vascularized fascia lata. Journal of reconstructive microsurgery, 2012. 28(03): $p$. 205-210.

7. Shimizu, F., et al, Algorithm for reconstruction of composite cranial defects using the fascial component of free anterolateral thigh flaps. Journal of Craniofacial Surgery, 2013. 24(5): p. 1631-1635.

8. Song, Y.-g., G.-z. Chen, and Y.-I. Song, The free thigh flap: a new free flap concept based on the septocutaneous artery. British journal of plastic surgery, 1984. 37(2): p. 149-159. 